Portland State University

PDXScholar

1978

\title{
A Validation Study of the Family Environment Scale: Family Incongruence Score
}

Linda Joanne Neale

Portland State University

Follow this and additional works at: https://pdxscholar.library.pdx.edu/open_access_etds

Part of the Family, Life Course, and Society Commons, and the Psychology Commons Let us know how access to this document benefits you.

\section{Recommended Citation}

Neale, Linda Joanne, "A Validation Study of the Family Environment Scale: Family Incongruence Score" (1978). Dissertations and Theses. Paper 2694.

https://doi.org/10.15760/etd.2690

This Thesis is brought to you for free and open access. It has been accepted for inclusion in Dissertations and Theses by an authorized administrator of PDXScholar. Please contact us if we can make this document more accessible: pdxscholar@pdx.edu. 
AN ABSTRACT OF THE THESIS OF Linda Joanne Neale for the Master of Arts in Psychology presented May 3, 1978.

Title: A Validation Study of the Family Environment Scale: Family Incongruence Score

APYROVED BY MEMBERS OF THE THESIS COMMITTEE:

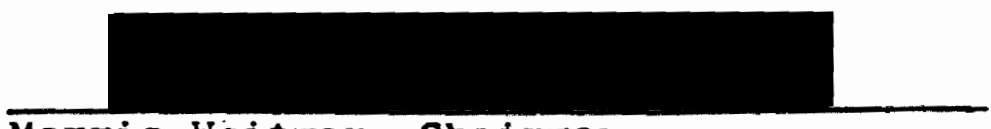

Morris Weitman, Chairman

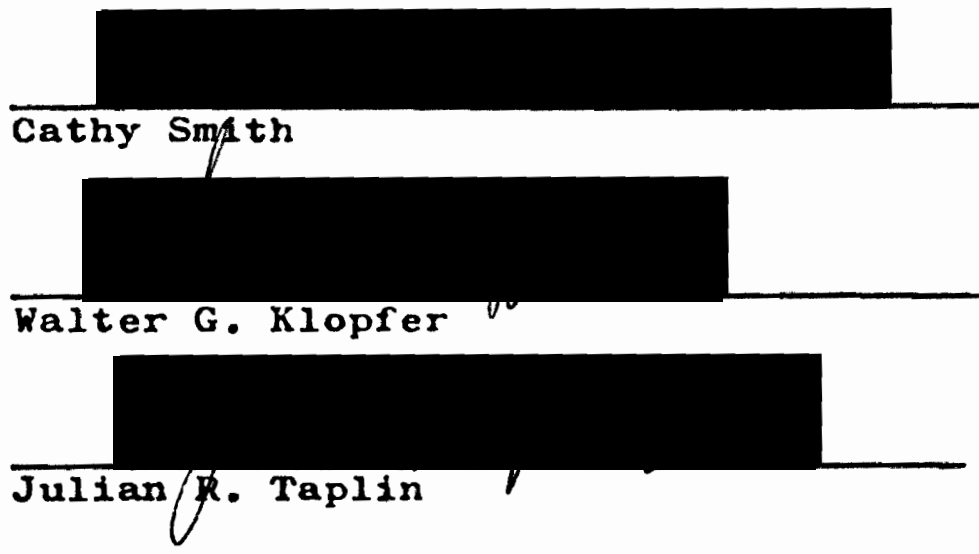

This study investigated the validity of the family incongruence score, a statistic which quantifies the discrepancies between family members' perceptions of their family system using answers given on the Family Environment Scale. Based on findings concerning incongruence in other environments, it was hypothesized that high family incongruence scores would be associated with more problems in the family system.

Twenty-six families who were reforred to a community 
mental health center for delinquency-related problems and twenty-six matched "healthy" families served as subjects. The Walker Problem Behavior Identification Checklist served as an indicator of the degree of behavioral disturbance of the target child in the clinic families both pre- and posttreatment. In addition, these familles were administered the Family Environment Scale pre- and post-treatment, and therapists rated the functioning of the family posttreatment only. The "healthy" or criterion families were administered the Family Environment Scale one time only. Results indicated that a) family incongruence scores for the clinic families were significantly larger than those of the "healthy" families both before and after treatment $(p<.005, p<.01) ; b)$ pre-treatment family incongruence scores were significantly larger than post-treatment scores for the clinic sample (p<.05); c) Walker Problem Behavior Identification Checklist scores were significantly correlated with family incongruence scores pre-treatment only $(r=.44, p(.01)$; d) Walker Problem Behavior Identification Checklist scores were negatively correlated with therapist ratings of family dysfunction $(r=-.57$, $\mathrm{p}(.001)$

In addition to the above results which were directly concerned with the original hypotheses of this study, further analysis of the Family Environment Scalo data indicated important and significant differences between clinic and "healthy" family profiles, between clinic and normative 
profiles, and between "healthy" and normative profiles. The results of this study support the notion that high family incongruence is associated with more problems in the family system. Further research is suggested in order to clarify what particular family behaviors are associated with high incongruity, and what behaviors or presenting problems are associated with different proftles on the Family Environment Scalo. 
A VALIDATION STUDY OF THE FAMILY ENVIRONMENT

SCALE: FAMILY INCONGRUENCE SCORE

by

Linda Joanne Neale

A thesis submitted in partial fulfillment of the requirements for the degree of

\author{
MASTER OF ARTS \\ in \\ PSYCHOLOGY
}

Portland State University

1978 
TO THE OFFICE OF GRADUATE STUDIES AND RESEARCH:

The members of the Committee approve the thesis of Linda Joanne Neale presented May 3, 1978.
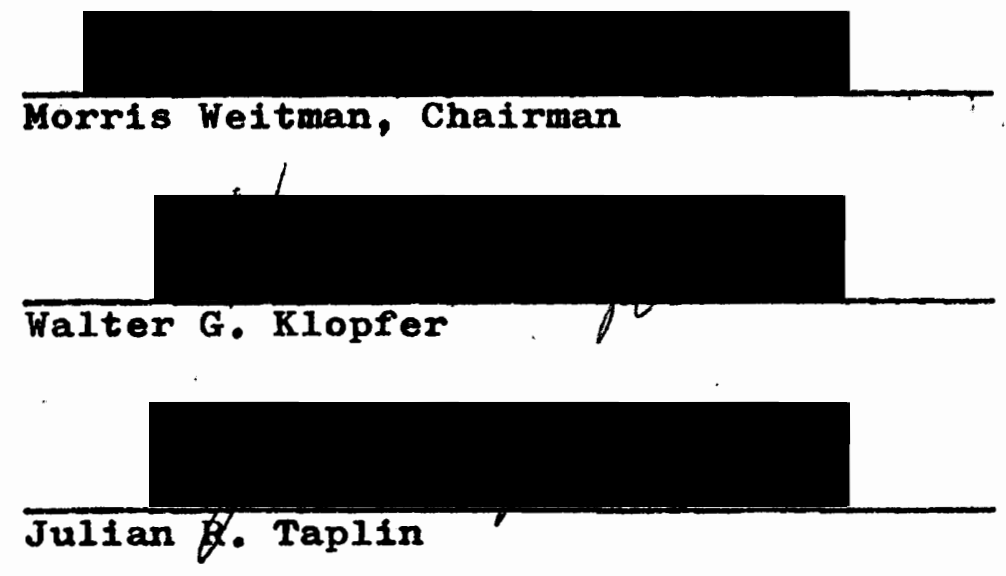

Cathy Smith

APPROVED:

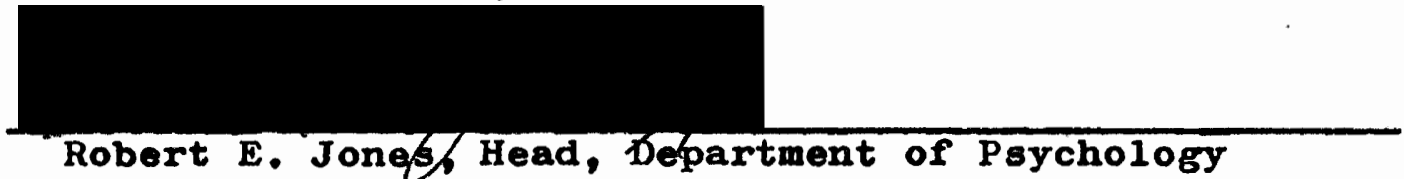

Robert E. Joneg, Head, Department of Psychology

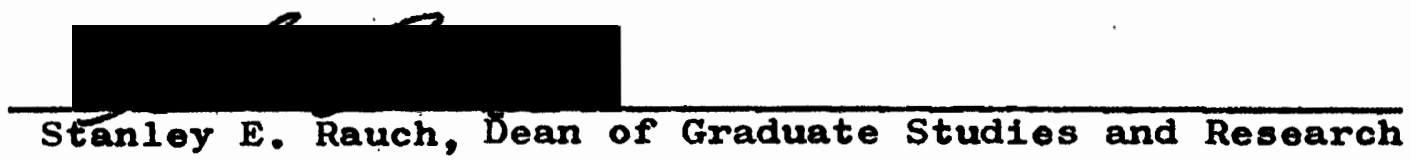




\section{ACKNOWLEDGEMENTS}

I wish to thank Morris Weitman, Julian Taplin, Cathy Swith, and Walter Klopfer, my committee, for their time and patience during the prolonged writing of this thesis. A special thanks is also due to the staff of the Intensive Family Intervention program: Molly Dinsdale, Michael Morrissey, and Connie McCutcheon, for their energy, Ideas, and support in ways too numerous to mention. I'd also like to express appreciation to Chris Garcia and Lynne Morrison for help in data collection, and to Gene Morrill for moral and statistical support. 
TABLE OF CONTENTS

PAGE

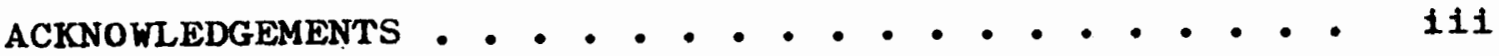

LIST OF TABLES • • • • • • • • . • . • • • • • • vi vi

LIST OF FIGURES - • • • • • • • • • • • • • • • viI

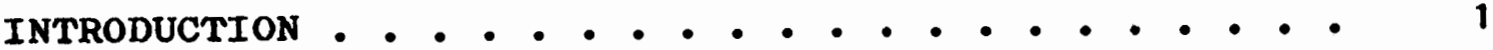

REVIEW OF THE LITERATURE

Background of the Family Environment Scale . . . 5

Research on Family Environment Scale Subscales • . 7

Research on Family Incongruence..$\cdot$...$\cdot$. 11

Incongruence in Other Environments . . . . . . . 12

HYPOTHESES • • • • • • • • • • • • • • • • • 13

METHOD

Clinic Subjects . . . . . . . . . . • . . .

Intensive Family Intervention Program . . . . . 16

Criterion Subjects. . . . . . . . . . . . 17

Procedure . . . . . . . . . . . . . . 18

Data Analysis . . . . . . . . . . . . 20

Information on Test Instruments . . . . . . . 20

RESULTS

Findings Related to Hypotheses . . . . . . . 24

Supplemental Findings . . . . . . . . . - 25

DISCUSSION

Relationship of Family Incongruence to

Other Variables . . . . . . . . . . . . 
PAGE

Family Environment Scale Profile Differences . . 33

SUMMARY AND RECOMMENDATIONS • • • • • • • • • • • : 37

BIBLIOGRAPHY . . . . . . . . . . . . . . . 40

APPENDIX

Therapist Rating Scale... . . . . . . . 43 


\section{LIST OF TABLES}

TABLE

PAGE

I Distribution of Clinic and Criterion

Groups by Head of Household

Occupation Category . . . . . . . . . 


\section{LIST OF FIGURES}

FIGURE

PAGE

1. Family Environment Scale Subscales : . . . 6

2. Expected Relationships Between Measures . . 14

3. Average Family Incongruence Scores for

"Healthy" and Clinic Samples . . . . . 24

4. Family Environment Scale Average Subscale

Scores for clinic and criterion

Samples.. . . . . . . . . . . . 26

5. Walker Problem Behavior Identification

Checklist Scores . . . . . . . . . . 28

6. Outcomes of Hypothesized Relationships

Between Measures . . . . . . . . . 38 


\section{INTRODUCTION}

Family therapy is being used as the treatment of choice for an increasing number of psychological and behavioral disorders (Kovel, 1976). In part, this is a reflection of a new emphasis on environments and their impact on individual behavior. Emotional/behavioral disturbances of family members are now seen more as a function of the interpersonal and organizational dynamics of the total family system or environment, rather than as primarily the result of an intrapsychic conflict. Goals of family therapy often include system changes such as reduction of conflict between family members, clarification of roles, or change in communication patterms (Minuchin 1974, Satir 1967).

Until recently, however, little research has been done on the effectiveness of family therapy, partly because no tool was availabie which could measure family system variables reliably. Traditional tools used in outcome evaluation such as the MMPI, Personal Orientation Inventory, and California Personality Inventory are primarliy concerned with the measurement of individual system factors, not family system factors (Sundberg, Tyler, and Taplin 1973); and although there are many measures available for application as family diagnostic and evaluation tools, very few of them have been adequately tested or validated. In Straus' (1969) review of family measurement techniques, he cautioned that the majority of instruments offered no substantial evidence 
of validity. In a more recent review of family and marital diagnostic tools, Cromwe11, 01son, and Fournier (1976) suggest that little progress has been made on validating existing measures. They recommended that evaluation of family and marriage diagnostic instruments and techniques be a priority to cliniclans and researchers alike, or else meaningful evaluation of family therapy itself will not be possible.

The purpose of the present study was to investigate the validity of the family incongruence score which is one major aspect of the Family Environment Scale (FES), a family measurement tool developed in 1974 by Rudolf H. Moos. The FES attempts to measure the social environments of all kinds of families, focusing on three areas: interpersonal relationships among family members, directions of personal growth emphasized within the family, and the basic organizational structure of the family. There are ten subscales contained within these three areas -- Cohesion, Expressiveness, Conflict, Independence, Achievement Orientation, IntellectualCultural Orientation, Active Recreational Orientation, Moral-Religious Emphasis, Organization, and Control - which are described in detail on page 6. The FES is a short, self-administered questionnaire which is given to everyone in the fanily who is able to read and comprehend the questions (usually age 10 and over). When the scale scores are plotted on a profile, it is possible to ascertain both where the family lies in relationship to the norm, and to what ex- 
tent family members disagree among themselves on their perceptions of the family environment. Using a special formula (see page 21) it is possible to quantify the amount of disagreement among family members on all ten scales and derive what is called the family incongruence score. In studies which focused on environments other than the family (i.e., correctional and psychiatric institutions), high incongruence was associated with more problems, lack of communication, discomfort, and rigid role definitions (Moos 1975, Maddi 1968). Moos (1974c) suggests that high incongruence in the family environment also may be associated with problems and a disturbed family situation, although he gives no direct evidence to support this hypothesis. The meaning and validity of family incongruence was the particular focus of the present study.

In this study, family incongruence scores for a group of famlies receiving treatment at a community mental health clinic were compared first with scores from a matched group of "healthy" families. Secondly, the behavior of the target child* in the clinic families was measured both before and after treatment using the Walker Problem Behavior Identification Checklist (WPBIC), and these scores were compared with the incongruence scores for families of these children. The rationale for this second approach is found in the family system literature which suggests that a problem child reflects

*In this case the target child, or identified patient, was referred for delinquency or pre-delinquency problems. 
problems within his/her family system, a notion first postulated by Ackerman (1958) who saw the symptomatic child as the emissary of the sick family and elaborated by more recent authors (Lewis, Beavers, Gossett, and Phillips 1976, Sundberg et. al. 1973). High WPBIC scores would thus be indicative of a dysfunctional family system. Thirdly, therapist ratings of family dysfunction were compared with clinic family incongruence scores after treatment only, when therapists were better able to judge degree of dysfunction.

The general hypothesis of this study was that high family incongruence scores would be associated with more problems and greater dysfunction in all three cases mentioned above. If this were the case, then the usefulness of the Family Environment Scale as a family diagnostic and outcome evaluation instrument would be strengthened. 
Background of the Famdiy Environment Scale (FES)

The FES is based largely on the work of Henry A. Murray. He formulated the idea of environmental "press", that is, whether an environment exerts a facilitative or obstructing effect upon an organism. According to Murray (1964), all environments can be classified according to their kind and degree of press, whether it is nourishing, or restraining, or helpful, or injurious to the organism. Moos expanded this idea in the development of nine social climate scales, one of which (the FES) assesses the family system. The logic of his approach is that "...the consensus of individuals characterizing their environment constitutes a measure of environmental climate, and that this environmental climate exerts a directional influence on behavior (of the people involved)" (Moos 1974c, page 1). The initial FES item pool was obtained by interviewing many people regarding their families, and adapting some items from other social climate scales. Each Item had to suggest that the family environment exerted a press toward one of twelve dimensions of family functioning. It is not clear from the literature how these dimerisions were developed, except that the authors thought they would differentiate among families. Sound psychometric test construction criteria were used in the development of the final form: 1) the overall item split was close to 50-50 in order to avoid items character- 
istic only of extreme families; 2) all of the final 90 items correlated more highly with their own than with any other subscale; 3) each of the subscales had an approximately equal number of 1 tems scored true and scored false in order to control for acquiescence response set; 4) the final subscales had only low to moderate intercorrelations;

5) each item and subscale maximally discriminated among families (Moos 1974c). Figure 1, below, lists the final ten subscales of the FES, with a short description of each scale (Moos 1974d).

FES

Subscales

Relationship Dimensions

1. COHESION

The extent to which family members are concermed and committed to the family and the degree to which family members are helpful and supportive of each other.

2. EXPRESSIVENESS The extent to which family menbers are allowed and encouraged to act openly and to express their feelings directiy.

3. CONFLICT

The extent to which the open expression of anger and aggression and generally conflictual interactions are characteristic of the family.

\section{Personal Growth Dimensions}

4. INDEPENDENCE

5. ACHIEVEMENT ORIBATTATION

6. INTELLECTUALCULTURAL ORIENTATION

The extent to which family members are encouraged to be assertive, selfsufficient, to make their orn decisions and to think things out for themselves.

The extent to which different types of activities ( $i . e .$, school and work) are cast into an achievement oriented or competative framework.

The extent to which the family is, concerned about political, social, intellectual, and cultural activities. 
7. ACTIVE

RECREATIONAL

ORIENTATION

8. MORAL-RELIGIOUS EMPHASIS

9. ORGANIZATION

10. CONTROL
The extent to which the family participates actively in various kinds of recreational and sporting activities.

The extent to which the family actively discusses and emphasizes ethical and religious issues and values.

System Maintenance Dimensions

Measures how important order and organization is in terms of structuring the family activities, financial planning and the explicitness and clarity in regard to family rules and responsibilities.

Assesses the extent to which the family is organized in a hierarchical manner, the rigidity of family rules and procedures and the extent to which family members order each other around.

Figure 1. Family Environment Scale Subscales

Research on the FES subscales

Little research has been published on the FES since Its develiopment in 1974, although Dr. Elizabeth Bromet, a research assistant to Dr. Moos at the Social Ecology Laboratory, reported to this investigator that the FES is widely used both for family diagnostic purposes and outcome evaluation studies. Moos (1974d) found that the FES is sonsitive to parent-child differences in the way families are perceived, and can discriminate between psychologically disturbed and matched normal families. In addition, ho reported that family size was related to scores on the Cohesiveness, Expressiveness, and Conflict subscales, with a tendency for Cohesiveness and Expressiveness to decrease and for Conflict to increase with increasing family size. These results were obtained from his original sample of 
285 families, including families recruited from churches,

a Mexican American and Black population, a psychiatricallyoriented family clinic, a probation and perole department, and a high school.

The FES also has been used to assess the social environments of problem drinkers (Moos, Bromet, Tsu, and Moos 1976). The scale was given to families of 122 treated problem drinkers and the results related to five sets of variables: socio-demographic variables, stress and illness variables, family activity and participation variables, interpersonal functioning variables, and variables related to the outcome of treatment for alcoholism. The socioeconomic variables which were related to the family environment were family size and parents' educational level. In terms of stress and illness variables, families which had a larger number of negative life change events also had greater emphasis on Conflict and Control in their families. Other important findings from this study were that there were relationships between the outcome of treatment for alcoholism (as indicated by a subjective rating of the extent of the drinking problem and psychological well being) and the family social milieu. Active Recreational Orientation and MoralReligious Emphasis were positively related to the functioning of the alcoholic member; poor functioning was related to high Conflict and Control, low Cohesion, Expressiveness, Independence, and Organization. James and Hesselbrock (1976) administered the FES to 
twenty-four children of schizophrenic parents and twenty-six children of normal parents. Children of schizophrenic parents rated their families significantly lower on two subscales: Intellectual-Cultural Orientation and Active-Recreational Orientation. When teachers assessed the school adjustment of twenty-three of these children, it was found that the only subscale which correlated with school behavior was Independence. Teenagers who percelved their families as stressing independent thought and action were more likely to be rated by teachers as higher in reasoning ability, originality, verbal interaction, and intellectual independence; as less anxious; and as having better work habits. The authors' conclusions were that competent children are reared in homes that encourage cogntive and social initiative.

A fow studies were concerned with the family environments of "disturbed" families. Scoresby and Christensen (1976) administered the FES to thirty-one families, thirteen of whom where receiving counseling at a university counseling clinic and eighteen who were not. The "disturbed" families scored significantly lower on Cohesion, Expressiveness, and Organization, and significantly higher on Conflict. Rosenthal (1975) used three subscales of the FES as one technique for evaluating the effects of behaviorally oriented parent training groups. Seventeen families, each having a child with behavior problems, were randomly assigned to a parent training group or a no-treatment control group. The ohildren in the experimental group showed a significant decrease in targeted deviant behaviors at post-treatment 
and follow-up, and their parents showed a significant decrease in their perception of problem behavior. In terms of the FES, parents in the experimental group perceived significantIy more Cohesion and less Conflict after the training, while there were no changes reported in the control group. Wetzel (1976) tested the hypothesis that a person is valnerable to depression if his/her tendency toward dependence or independence is not supported by the environment. Two measures of predisposition toward dependence or independence were developed in a preliminary study. Then subscales from the FES and the Work Environment Scale (WES) and a twenty 1tem depression inventory were administered to 100 working women with families, fifty of whom were diagnosed as clinically depressed. In terms of subscales of the WES, depressed women perceived significantly less Peer Support and Autonomy, and significantly more Control in their work environments than did non-depressed women. They also perceived significantiy less Cohesion in their family environments. Women who had a predisposition towards independence, but who were not in an autonomous family environment ( 1.0. , high scorers on the FeS subscale of Independence) tended to be depressed. Dependent women who perceived their work environments as low in Clarity (i.e., as not giving them needed structure) tended to be depressed, as did independent women who perceived their work environment as high in clarity (giving them too much structure). The author saw these incongruities between predisposition and the work and 
family environments as a possible cause of depression.

Bader (1976) used the FES as one techniques with which to evaluate a one week family therapy workshop. The FES was given to five experimental and five control families before and after the workshop, and at a two month followup. The families in the experimental group showed significant increases in Cohesion, Expressiveness, and Independence from before to immediately after the workshop, and additional increases at followup. The control group showed no significant changes on any FES subscale.

\section{Reseerch on Family Incongruence}

This author found only one study which addressed the issue of family incongruence. Moos and Moos (1976) picked a sub-sample of 100 families from their original 285 and cluster analyzed their FES scores. Using this statistical procedure, they identified six different clusters of families: expression-oriented, structure-oriented, independenceoriented, achievement-oriented, moral religious oriented, and conflict-oriented. The clusters showed systematic differences in background characteristics such as size, ethnic minority composition, drinking patterns, family disturbance, and incongruence. The authors observed that families with high incongruence scores were over-represented in the achierement-oriented and conflict-oriented clusters, but they did not speculate on possible reasons for this. 
Inconeruence in Other Environments

In his book Evaluating Correctional and Communtty

Settinge, Moos devoted a chapter to incongruence in correctional institutions, some of which is relevant to this study. He cited an earlier work (1974b) which showed that patients and staff of psychiatric programs usually agree quite well on their perceptions of the treatment environment ( 1.0. , have high congruence), and mentioned two processes which contribute to the congruence:

First, patients and staff learn about the characteristics of their treatment milieus, and congruence develops out of a mutually shared reality of events. Congruence also develops through discussions of shared value orientation and through mutual attraction and personal influences directed toward increasing congruence. Second, patients and staff who do not share elther the perceptions of the treatment miliou and/or the dominant value orientations about an ideal milieu tend to leave the program. (Hoos 1974b, page 208)

Using the Correctional Institutions Environment Scale (CIES), he found that this congruity did not hold when applied to correctional settings. Instead, he discovered that staff and residents had almost no agreement on the characteristics of thei $r$ programs. This result held when the CIES was applied to a larger sample of 78 correctional units. Moos explained this difference between psychiatric and correctional settings by noting a lack of communication between residents and staff in a correctional setting, which he felt contributed to the cultural and social disorganization of correctional programs.

At the end of this chapter, Moos reviewed: number of studies which focused on the importance of value congruence 
or stmilarity, especially between patients and therapists, but also between student needs and their school environments and concluded:

-. .the evidence indicates that lack of congruence is usually associated with more problems, individual symptons, and so forth. (Moos 1974a, page 212)

\section{Hypotheses of the Bresent Study}

This study attempted to explore the relationship between incongruence scores on the Family Environment Scale and family problems. Do Moos' findings regarding the corralation of high incongruity with more problems hold in family environments as well as institutional environments? If so, this study would provide some further validation for use of the Family Environment scale in famlly therapy or as an outcome measure in other interventions.

Four measures were utilized in this study: a) an indicator of the degree of behavioral disturbance of the target child (Walker Problem Behavior Identification Check1ist); b) an indicator of family dysfunction (Therapist Rating Scale); c) a measure of incongruity for a group of dysfunctional families (family incongruence scores) and d) a measure of incongruity for a criterion group of wellfunctioning or "healthy" families (family incongruence scores). Specifically, it was hypothesized that:

1. Family incongruence scores both before and after treatment would be significantly larger for dysfuncti onal (clinic) families than for the criterion or "healthy" families. 
2. Therapist ratings of family dysfunction would be positively correlated with family incongruence scores for the cilnic families after treatment.

3. Scores on the Walker Problem Behavior Identification Checklist (WPBIC) would be negatively correlated with therapists' ratings of family dysfunction after treatment.

4. Scores on the WPBIC would be positively correlated with family incongruence scores for dysfunotional families both before and after treatment.

The expected outcomes of the study are graphically illustrated In Figure 2, below. Each vertical line indicates an expected correlation between measures; each horizontal or diagonal 1ine indicates an expected significant difference between messures .

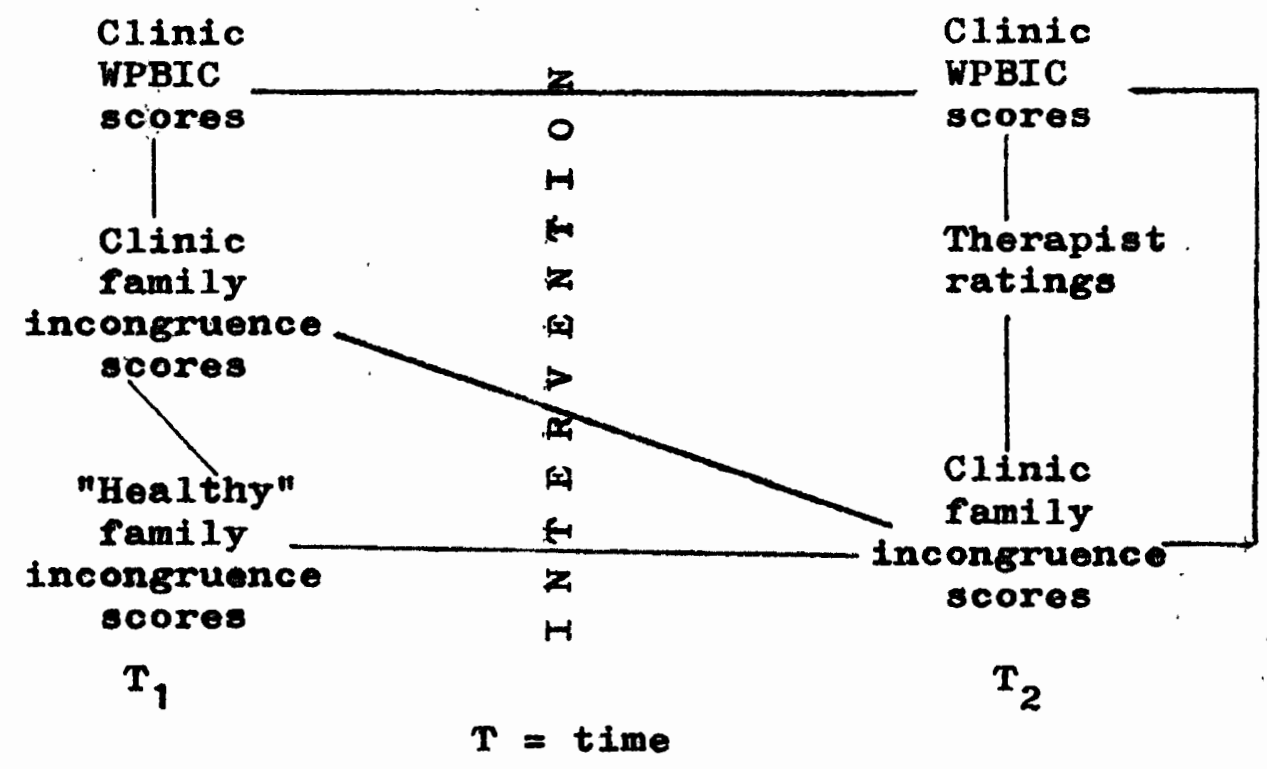

Pl mure 2, Expected telatiomships between measures. 


\section{METHOD}

\section{Clinie Subjects}

The clinic subjects in this study were 106 people from 26. families who participated in an Intensive Family Intervention (IFI) program at a mental health center in Portland, Oregon. The program was designed to serve familles with at least one child between the ages of 9 and 16 who was identified as delinquent or pre-delinquent. Juveniles who were serious status offenders*, had committed non-status crimes, or showed high probability of future involvement in the juvenile justice system were eligible for referral. The average age of the delinquent (or "target") child was 13.5 years. Sixty percent of these children had been involved with the juvenile justice system before they entered treatment. Twenty-three percent came from situations in which there was only one parent in the home. Sixty-two percent of the families lived in southeast Portland, an area which is primarily composed of white, working class, lower-middle income families. All of the individuals in this study were white, and $19 \%$ were on welfare or some other form of public assistance. Fifteen percent of these families had one child, $35 \%$ had two children, and $50 \%$ of these families had three or more children. Generally, these families did nat seek out

* Status offenders are children who commit status offenses -- offenses which would not be considered crimes If the person were over 18 , e.g., runaway or beyond parental control. 
treatment, but were referred by other agencies. S1xty percent of all referrals came from the police or juvenile court; the rest were from Children's Servioes Division (a mocial service agency in Oregon), schools, or other youth agencies. Only ten percent of the clinic families were self-referred. They were not forced to enter this program, although many were strongly encouraged to participate by the referring agencies.

Intensive Family Intervention Program (IFI)

The general goals of IFI were twofold: a) to intermupt and redirect behavior patterns of target children 80 that the children did not continue to be involved in the juvenile justice system, and b) to increase each family's capacity for constructive problem solving and mutual support. Multiple therapeutic approaches were used with each family, including a parent training group, adolescent socialization groups, and family therapy meetings. The parent group focused on teaching skills including behavior modification techniques and communication, and imparting knowledge of child and adolescent development. There was a heavy emphasis on adapting new skills to other situations; consequently, home visits and school contacts were made periodically. IFI was designed to serve 48 familles per year in three cycles of 16: families each. The average number of service hours received by each family during the four month program was 50 hours per family. 


\section{Criterion Group Subjects}

The critertion or "healthy" sample was matched with clinic families on six variables including age of children, number of children in the family, number of parents in the home, race, area of residence, and occupational level of parents. 102 people in 26 families made up this group; $15.4 \%$ had only one child, $38.5 \%$ had two children, and $46.1 \%$ had three or more children. Nineteen percent of the families had only one parent in the home, and $67 \%$ of the families lived in southeast Portland. These figures on family size and number of parents are comparable to those of the clinic sample. It was not possible to obtain an equal number of families who were receiving public assistance and met the other qualifications for this group: only two families or 7\% of this group were receiving welfare. It was also not possible to match the criterion and clinic groups on reIIgious affiliation.

Al1 26 families in this group were "healthy" in that no one in the family was under psychological or psychiatric care, and none of the chlldren were behavior problems in school or had been in a foster home or other institutional care.

The clinic and criterion samples were matched for head of household occupation using a modification of Hollingshead's Two Factor Index of Social Position (1957). This scale ranks professions into seven different groups: 1) executives and proprietors of large concerns and major 
professionals, 2) managers and proprietors of medium concerns and minor professionals, 3) administrative personnel of large concerns, owners of small independent businesses and semiprofessionals, 4) owners of little businesses, clerical and sales workers, and technicians, 5) skilled workers, 6) semiskilled workers, and 7) unskilled workers. The distribution of the two samples by category is given in Table I.

\section{TABLE I}

DISTRIBUTION OF CLINIC AND CRITERION GROUPS BY HEAD OF HOUSEHOLD OCCUPATION CATESORY

\begin{tabular}{llllllllll}
\multicolumn{7}{c}{ Occupation Category } \\
& 1 & 2 & 3 & 4 & 5 & 6 & 7 & $\bar{x}$ \\
\hline \# clinic & 5 & 4 & 5 & 6 & 2 & 1 & 3 & 3.4 \\
\# criterion & 7 & 5 & 3 & 5 & 1 & 2 & 3 & 3.2 \\
\hline
\end{tabular}

The criterion group was slightly over-represented in categorles 1 and 2 however, the average scores for the two groups were almost identical and were not significantly different.

\section{Procedure}

After the initial referral was made to the clinic, subject families were contacted by their assigned therapist and scheduled for an initial interview which all family members were required to attend. During the first part of this meeting, the experimenter gave the Family Environment Scale to each family member over age 10 (some exceptions 
were made for younger children who demonstrated that they could understand the questions), and gave the Walker Problem Behavior Identification Checklist to each parent to complete about their target child. The family was instructed not to discuss the tests but to ask the experimenter If they had any questions. The families were told that these questionnaires would be seen only by their therapist and the experimenter, and that all results would romain confidential. They were also told that they would be asked to fill out the same forms at the end of the four month program.

The criterion subjects were referred to the experimenter by a school principal, minister, or mental health worker as being, in the opinion of the referring person, a well-functioning family. The original proposal called for these families to be contacted through the public schools alone, but due to school confidentiality laws, it was not possible to obtain enough families from this source. After three months, only ten families were referred from schools, six of whom agreed to participate in the study. Churches were more cooperative, and an additional thirteen families were obtained from ministers. Each criterion family was contacted by the experimenter and asked to participate in a study of family relations. They were also asked questions concerned with family demographice:arid to establish that the family did or did not meet the criteria for a "healthy" family. They were told that the results 
would be confidential and that they would be helping the experimenter by volunteering to answer a questionnaire about their family. If they agreed to participate, an appointment was made for testing at their home, during which all family members were asked to be present. The experimenter or an asisistant administered the scale at that time, ensuring that all tests were done independently. Additional information such as number of children, parents' occupation, and area of residence was also noted. Originally, information concerning income was collected, but many families did not feel comfortable giving that information, so it was not included.

\section{Data Analyses}

The data analyses involved Pearson product-moment correlations and t-tests for matched groups. For hypothesis 1, the t-test for related measures was used; correlation coefficients were calculated for hypotheses 2,3 , and 4, and tested for significance; additional statistical procedures such as analysis of variance and t-tests for independent samples were used for the supplemental findings. The Central Limit Theorem (Mosteller, Rourke, and Thomas 1965) was used to determine if the set of findings was significant.

\section{Information on Test Instruments}

Family Environments Scale, The FES was discussed in the introduction to this thesis, and a description of 
its ten subscales was given in Figure 1. The primary focus of this study, the family incongruence score, is calculated as follows: first, the raw scores for each subscale are found, then the differences between all possible pairs of individual subscale scores are calculated, the differences are summed and divided by the total number of score pairs. This is expressed in the following equation:

$$
\frac{x \sum_{T}^{10} j \sum_{T}^{N-1} i \sum_{T}^{N-1}\left|x_{k, i}-x_{k, i+j}\right|}{\frac{N !}{2(N-2) T}} \quad \text { where }\left\{\begin{array}{l}
N=\# \text { people } \\
k=\text { Fes subscales } \\
x_{i}=8 \text { subsale score } \\
+j \leqslant N
\end{array}\right.
$$

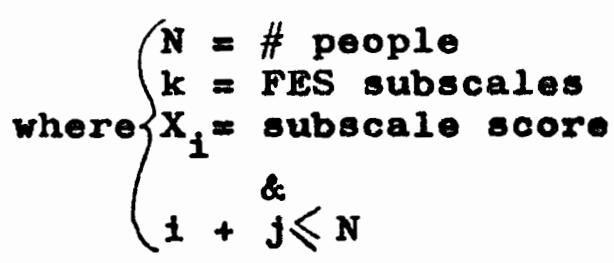

The family incongruence raw score is then converted into a standard score using the table provided in the Fes manual. Wazker Problem Behavior Identification Chocklist. The WPBIC was originally developed for classroom teachers in order to help them select children with behavior problems who needed further psychological evaluation, referral, or treatment. It is composed of fifty statements describing observable child behaviors whioh are divided into five subscales: Acting out, Withdrawal, Distractability, Disturbed peer relations, and Immaturity. The subscales also can be combined into an overall score for the total check1ist. A T-score of 60 overall, the equivalent of one standard deviation above the mean, was established as the point for separating disturbed from non-disturbed children. The WPBIC overall score has a reported Kuder-Richardson reliablity coefficient of .98 which makes it possible to distinguish among individuals with a considerable degree 
of confidence. The WPBIC is one of the fow behavior check1ists which has been evaluated for convergent validity (Bolstad and Johnson 1977), and used to predict behavior disturbance in school children (Walker. 1970). The results of both of these studies indicated that the validity of the WPBIC was sufficient to warrant its use as a measure of child behavior in the present study.

Therapist Rating Scale. The Therapist Rating Scale is a short, five point, Likert-type scale which was used to quantify the clinical impressions of therapists regarding the degree of family dysfunction (see Appendix). It was developed by the experimenter and participating therapists so that all those involved with the clinic families would understand what was meant by each point on the scale. The scale ranged from "1 - barely functioning" to "5 strong functioning ${ }^{n}$ and included definitions of these terms. The original intention was to calculate inter-rater reliability with all families who had two or more primary therapists working with them. Unfortunately, many therapists became involved in the Intensive Family Intervention proGram, and only rarely were the same two therapists working together with more than a few families. For example, only six families were seen by therapists $A$ and $B$; four families had therapists $A$ and $C$. Using the $r$ to $z$ transformation to average the correlations of the two groups, a correlation coefficient of .66 was obtained. This somewhat low reliability coefficient derived from a small $N$ 
suggests that the Therapist Rating Scale has limlted value or utility. 


\section{RESULTS}

Findings Related to Stated Hypotheses

The first hypothesis, that family incongruence scores for the clinic families would be larger than those of "healthy" families both before and after treatment was upheld. Additionally, pre-treatment family incongruence scores were significantly larger than post-treatment scores for the clinic sample (see Figure 3, below).

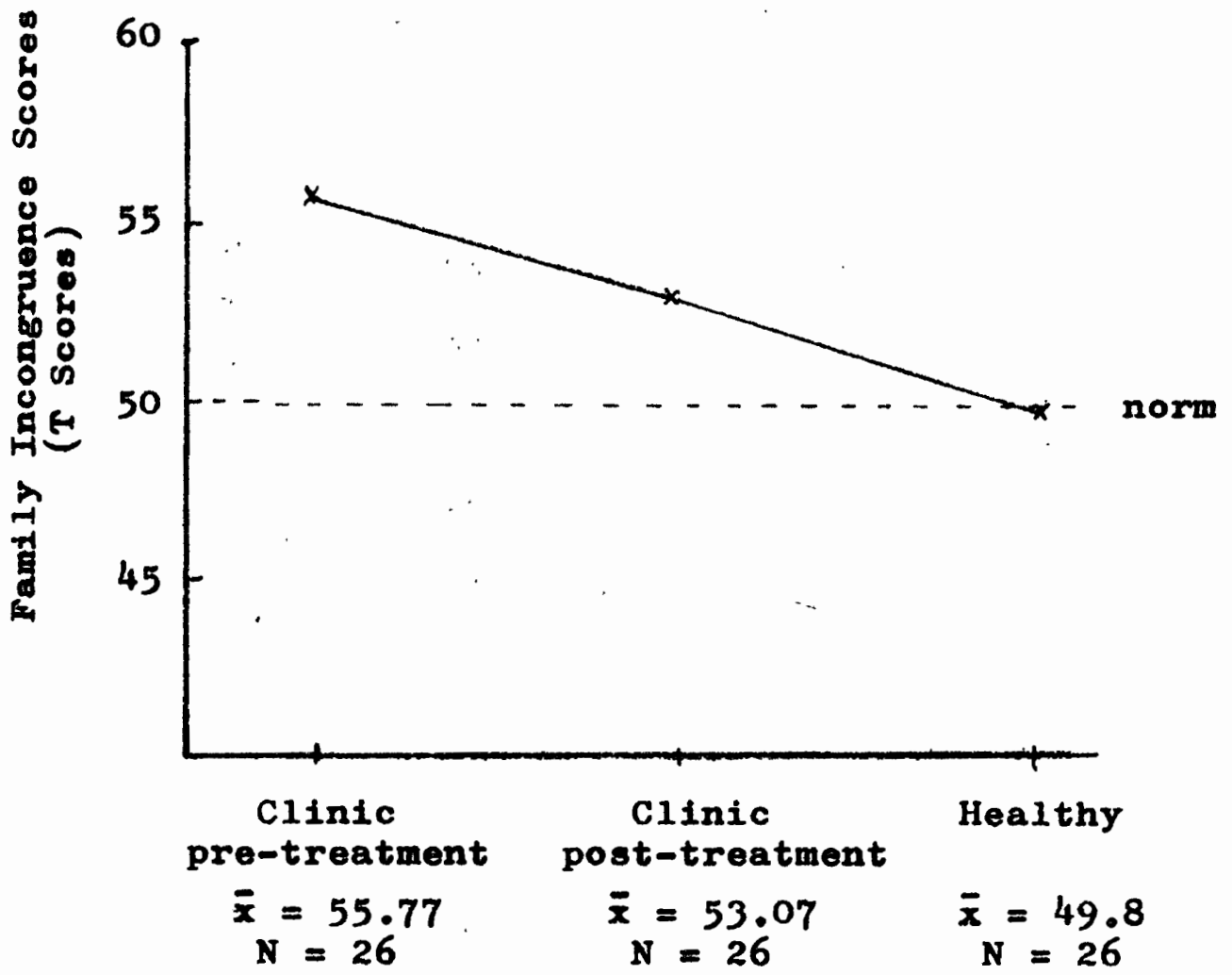

Figure 3. Average family incongruence scores for "healthy" and clinic samples. 
The difference between the clinic pre-treatment and healthy samples was significant at the $p<.01$ level $(t=3.27)$. The difference between the clinic post-treatment and healthy samples was significant at the $p<.01$ level $(t=2.66)$, and the difference between clinic pres and posttreatment groups was significant at the $p<.05$ level (t = 1.98)

The results for the other hypotheses were mixed. Hypothesis 2, that therapist ratings would be correlated with family incongruence scores after treatment, was not substantiated $(r=-.04)$. Hypothesis 3 , that WPBIC scores would be negatively correlated with therapist ratings was upheld $(r=-.57, p<.001)$. Hypothesis 4, that WPBIC scores would be positively correlated with family incongruence scores. both before and after treatment was only partially substantiated. These two measures were significantly correlated before treatment $(r=.44, p<.01)$, but there was no significant correlation after treatment $(r=-.22)$.

\section{Supplemental Findings}

In addition to the above results which are directly concerned with the original hypotheses of this study, further analysis of the Family Environment Scale data yielded the following results:

1. There were significant differences between the "healthy" and clinic pre-treatment samples on all FES subscales except Achievement Orientation (see Pigure 4). 


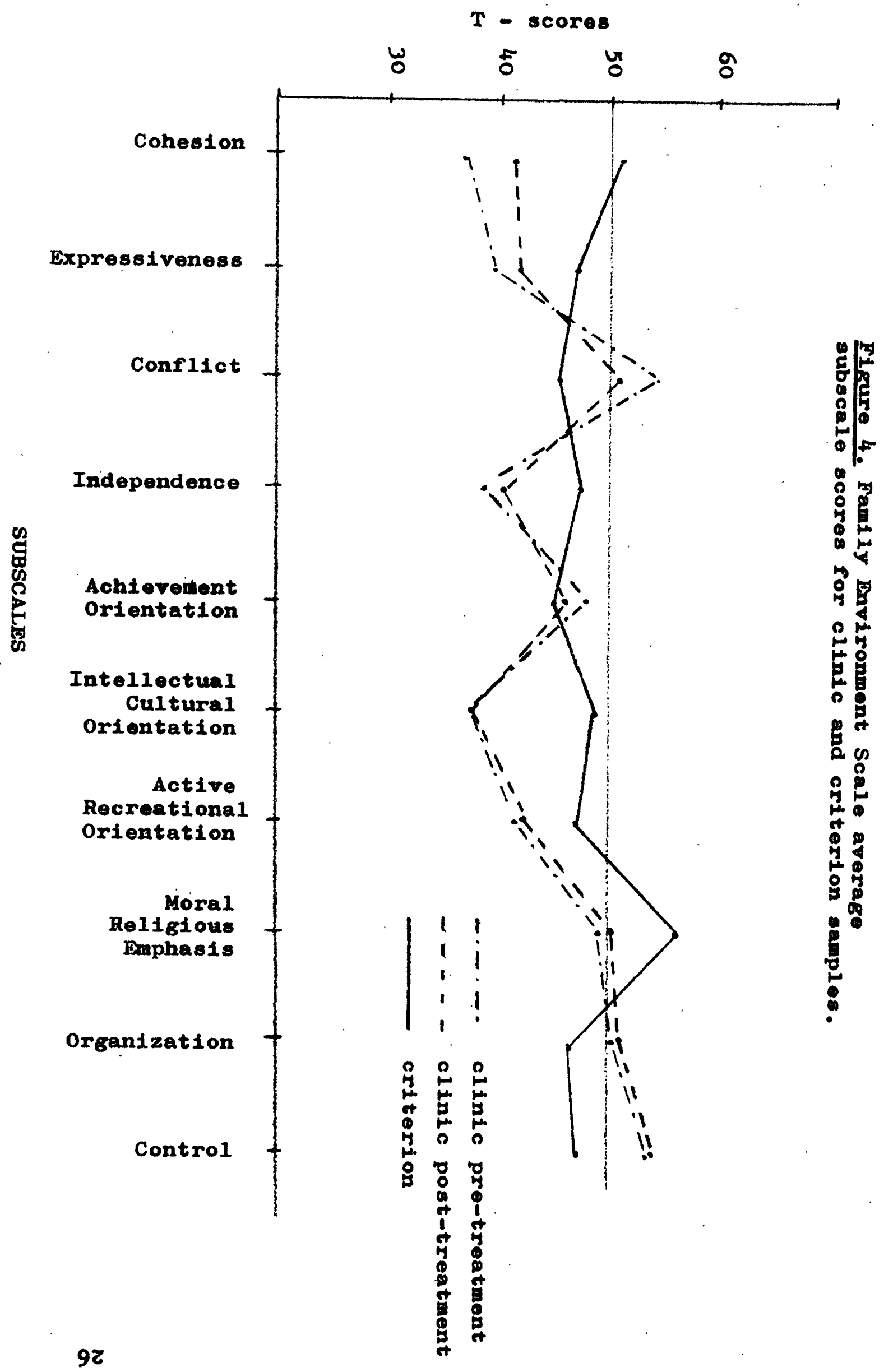


2. There were no significant differences betwoen clinic pre- and post-treatment groups on any FES subscales.

3. The "healthy" sample had scores significantly lower than Moos' (1974c) norms on Conf1ict $(p<.05)$ and Achievement Orientation $(p<.05)$, a marginally significantly lower score on Organization $(p<.05$, 1-tailed), and a significantly higher score on Moral-Religious Emphasis $(p<.001)$.

4. The clinic pre-treatment sample had scores significantly greater than the norm on Conflict $(p<.05)$ and Control ( $p<.05,1$-tailed), and significantly lower scores on Cohesion $(p<.001)$, Expressiveness $(p<.001)$. Independence $(p<.001)$, IntellectualCultural Orientation $(p<.001)$, and Active-Recreational Orientation $(p<.001)$.

5. There was a significant decrease in the number of problem behaviors reported by parents of the target child in the clinic sample. WPBIC scores declined almost one standard deviation from before to after treatment, a difference which was significant at the $p<.05$ level (see Figure 5).

6. Of the elght statistical analyses used to test the original hypotheses, six were significant at the .05 level or better. As determined by use of Central Limit Theory, the probability that 6 of 8 statistical tests would be significant is less than .001 (Mosteller et. al., 1961). 


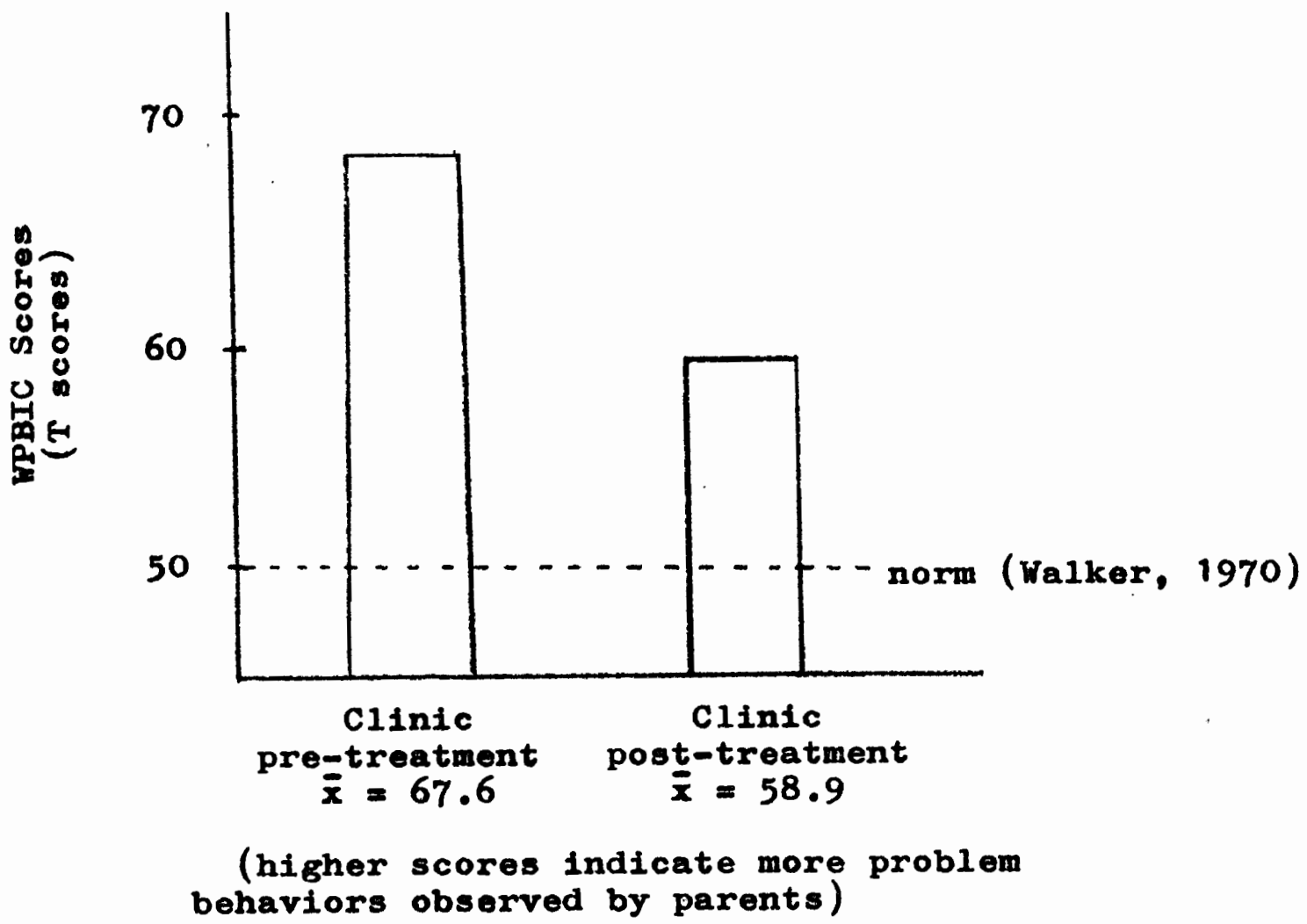

Figure 5. Walker Problem Behavior Identification Checklist scores. 


\section{DISCUSSION}

Relationship of Family Incongruence to Other Variables

Although the results of this study were mixed, there were sufficient data to suggest that high incongruence in families is indeed associated with more problems in the family system, as it is in other environments. Such a relationship is especially apparent in Figure 3 (page 24) which illustrates that dysfunctional families with a delinquent child (clinic pre-treatment group) had the highest average incongruence scores; these same families after a four month intervention program. (when the number of reported problems exhibited by the child had decreased) had significantly lower incongruence; and the lowest average incongruence was obtained by the "healthy" sample of families. This result alone provides some important validation of the family incongruence score, and partially substantiates Moos' (1976) findings on incongruence in other environments.

The relationship between parents' perceptions of child behavior (WPBIC scores) and family incongruence is puzzling at first. The results showed that in delinquent family environments before intervention, there was a significant correlation between the target children's behavior checklist scores and their family incongruence scores, as hypothesimed. After an intensive treatmont program, however, there was no relationship between these two scores. Something in the families changed during that four month period so that the 
incongruity remaining in the family systems was no longer related to the focal children's behavior, or else some otatistical artifact erased the correlation. One possible explanation, espoused by many family therapists, is that a delinquent child acts out problems which are in their family syster, (e.g. Satir, 1967). According to this idea, the child is a sort of barometer for family problems. The data from this study suggest that this theory may be valid when the problems are extreme. If the crisis passes and the child's behavior improves, family problems as reflected by incongruity may be tied to other aspects of family functioning, e.E., the marriage relationship. Another possibility is that parents paid less attention to the child's deviant behaviors as their own relationships improved. The lack of correlation post-treatment could also be explained statistically. The i. correlation of . 44 betireen checklist and incongruence scores means that $19 \%$ of the variance in WPBIC scores can be attributed to family incongruence or vice versa. Since both incongruence and behavior scores declined significantly after treatment, however, the amount of shared variance was drastically reduced and was no longer significant. Unfortunately, behavior checklists were not filled out by the criterion group, which could have shed some additional light on the problem. More research should be done to examine further the relationship between child behavior and family incongruence.

The lack of correlation between therapist ratings and 
family incongruence, although not hypothesized, can be explained in two ways. First, if therapists were judging family functioning according to the barometer theory mentioned above, then by focusing primarily on the child's behavior, therapists may have thought they were evaluating the whole family. Since the ratings were done post-treatment only, and there was no relationship between family incongruence and child behavior at that time, the therapists' judgnents which were made on the basis of the target child's behavior would not be related to incongruence in any way. Secondly, the clinic families were referred to the Intensive Family Intervention program because of the target child's acting out behavior, and parents often exerted pressure on therapists to "fix" the child rather than change the family system variables which were influencing the child. Families often resisted discussion of problems which were not directly related to the target child. Consequently, in some families the child's behavior may have been the only available window on the degree of family dysfunction for therapists. Another explanation for the lack of correlation could be the unreliability of the therapist rating scale itself (see page 22). In future research the use of a more reliable rating scale such as that used by Lewis et. al. (1976) would help clarify the relationship between child behavior and family incongruence.

In summary, this study found two factors which were related to family incongruence: 1) the presence or absence 
of problems severe enough to warrant intervention by social service agencies (reflected in the clinic and criterion samples respectively), and 2) parents' perceptions of children's behavior before intervention in the clinic sample (reflected in WPBIC scores for the target child).

A next step in examining the meaning of incongruence in the family would be to observe families in their homes in order to discover what behaviors, if any, are associated with high incongruity. This investigator's hypothesis is that inconsistency in punishment and other responses by parents to particular behaviors by children would be significantly correlated with incongruence. This hypothesis is supported by research on delinquency (Singer, 1974) and the structure of the disorganised family (Minuchin, Montalvo, Guerney, Rosman, and Schumer 1967), which indicates that parents' responses to children's behavior is based more on parental mood than on any action by the child. When children are receiving this random kind of parental input, there should be wide variations between members' perceptions of their family system.

If high family incongruence is associated with more problems as suggested, one goal of family therapy could be to reduce the incongruence and thereby reduce the number of problems. Moos (1975) gave some advice on ways of reducing incongruity in a correctional environment which could bo relevant to families as well. Although it may be stretchIng the imagination to consider parents as "staff" and 
children as "residents" or "inmates", try substituting those

famtly words in the following quotations:

The importance of increasing the degree of etaff interaction with residents can hardly be overemphasized. (p. 213)

The evidence that increased resident-staff contact ahould lead to increased resident-staff agreement and greater staff influence on residents is substantial. (p. 215)

Staff influence on inmates varies directly with staff manifestation to inmates of the same types of personal behavior that cause a man to be liked in non-prison relationships: a) Inmates are most influenced by staff who act towards them in a friendly and considerate -rather than hostile -- tone and manner. b) Inmates are most influenced by staff who treat them with fairness and predictability. (Glaser 1964, p. 133)

Some of this advice could have been taken from a text on parent training. The applicability of these statements to families as well as institutions highlights the consistency of system influences across environments.

\section{Family Environment Soale Profile Differences}

Perhaps some of the more interesting results cilnically were tangential to the original hypotheses of this study. The FES profiles of the clinic and criterion samples were very different, as can be seen in Figure 4. The clinic pre-treatment scores were characterized by low Cohesion and Expressiveness, high Conflict, low Independence, low soores on most personal growth dimensions, and high Control. There seems to be little holding these families together except conflict and control. This profile corresponds closely to Moos' (1975) high conflict family. This kind of profile 
may be particularly characteristic of delinquents and their families, or it may be that all families in crisis tend to show this low cohesion, high conflict profile. There are data which support both positions. For Instance, McCord, McCord, and Howard (1961) compared the family environments of nondelinquent but aggressive boys with those of nonaggressive boys. Aggressive boys came from homes characterized by rejection, punitive and inconsistent discipline, little adequate supervision, and conflict between the parents. Nonaggressive boys more often had affectionate relationships with thoir parents, adequate and firm supervision, and consistent, nonpunitive discipline. There was also little conflict between the parents. These and other data (e.g., McCord, McCord, and Zola 1959) support the position that delinquent fanily systems in particular are characterized by low cohesion and high confilct. However, Moos (1975) compared FES scores of 42 "clinic" families and 42 matched "normal" families. The clinic families, whose presenting problems were varied, obtained significantly lower scores on Cohesion, Intellectual-Cultural Orientation, and Active Recreational Orientation. They obtained higher scores on both Conflict and Control, and lower scores on Expressiveness and Independence, but these differences were not statistically significant. This kind of profile closely matches that found in the present study with delinquent youth and their families, except that in this delinguent sample the aubscale scores were more extreme. Extremity of 
scores may be the distinguishing factor between delinquent families and those with other kinds of problems, Further research needs to be done to determine if FES profiles can be correlated with presenting problems.

The prof1le of the "healthy" or criterion sample in the present study is also interesting. This group appears to have less conflict, less emphasis placed on achievement, and more emphasis on moral-religious attitudes than Moos' norm. Since a large portion (50\%) of this sample were referred by ministers, the peak on Moral-Religious Emphasis was not unexpocted. Is this a typical profile for a healthy famlly, or are there other profiles which are also healthy? Although there is no way of answering this question at present, research by Lew1s, Beavers, Gossett, and Phillips (1976) indicates that healthy familles have signiflcantly less confliot as measured by observer ratings than do families with neurotic, behavior disordered, or psychotic member. Most probably, however, there are several modes of healthy syotem adjustment with correspondingly different profile characteristics.

A final comment w111 be made concerning the similarIty between the pre- and post-treatment subscale scores for the olln1e sample. There are fow explanations which could acoount for this. The firet is that the subscales of the Fes cannot measure ohange in the family system. This oxplanation is contradioted by other researoh, however (Rosenthal 1975; Bader 1976). A second explanation is that 
the Intensive Family Intervention program did not significantly change the system variables measured by the FES subscales, although it did affect family incongruence and the behavior of the target child. If this second idea is correot, It could be that the family incongruence score is more sensitive to change than the individual subscale scores. A third explanation concerns the wide variation in treatment experienced by the clinic families. Not only were different families seen by different therapists with different styles, but some families had much more contact with the IFI program than others. Such a variation in treatment could influence subscale scores so as to eradicate any consistent average differences. 


\section{SUMMARY AND RECOMOYENDATIONS}

The focus of this study was on the validity of the family incongruence score, a statistic which quantifies the discrepancies between family members' perceptions of their family syotem on the Family Environment Scale. Based on Findings concerning incongruence in other environments, it was hypothesized that high family incongruence scores would be aswoclated with more problems in the family oystem. Four measures were utilized in this study: a) an Indicator of the degree of bohavioral disturbance of the target ch11d in 26 dyefunctional families (Walker Problem Beharlor Ident1fication Cheoklist); b) an indicator of degree of family dysfunction as perceived by therapists (Theraplot Rating Soale); c) a measure of incongruity for the same group of 26 families (family incongruence scores): and d) a measure of Inoongruity for a criterion group of matched, well-functioning families (famliy incongruence soores).

The outcomes of the study are show below in Figure 6. Each vertical IIno indicates a signifloant correlation botweon two measures; each hortzontal or diagonal 1 ine Indiontes a significant difference between the measures. A dashed line indicates a hypothesized relationship which was not oubstantiated by the results. 


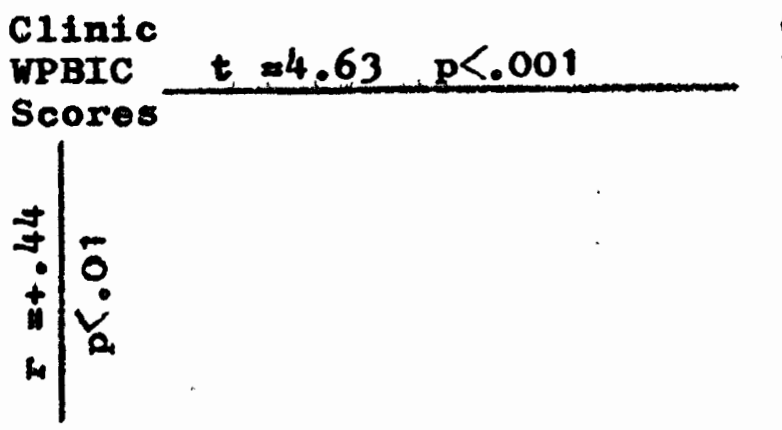

Ciinic

UPBIC

Scores $--i$

Clinic

Family

in

Therapist

Incongruence

Scores
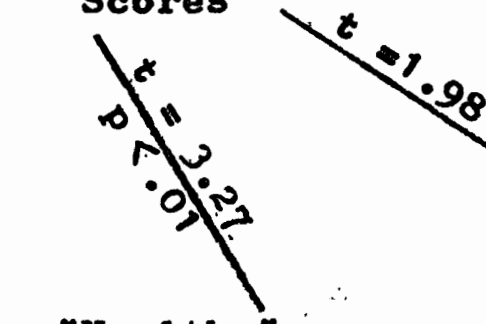

Ratings

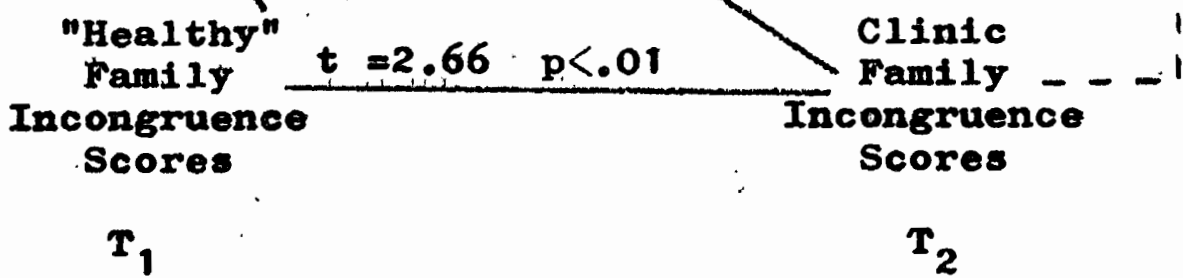

$\mathbf{T}=\mathbf{t i m e}$

Figure 6. Outcomes of hypothesized relationships between measures.

In addition to the above, there were important and significant differences between the clinic and healthy samples on the Family Environment Scale subscales.

In general, the results of this study lend support to the viow that high family incongruence is indeed associated with more problems in the family system. It also appears as though the family incongruence score is a more sensitive Indicator of change in the family system than the Family Environment Scale subscales. 
The results of this study suggest that delinquent families are likely to have a low cohesion, high conflict profile and that "healthy" families have lower than average conflict, and high moral-religious emphasis. Future research should Investigate this pattern further by observing families in order to discover what particular behaviors are associated with high incongruity, and what behaviors or presenting problems are associated with different profiles on the Family Environment Scale. 


\section{BIBLIOGRAPHY}

Ackerman, N.W. The psychodymamics of family life. New York: Basic Books, 1958.

Bader, E. Redicision in family therapy: a study of chango in an intensive family therapy workshop. Unpublished doctoral dissertation, California School of Professional Poychology, San Francisco, 1976.

Bolstad, Orin D. and Johnson, Stephen M. The relationship between teachers' assessment of students and the students' actual behavior in the classroom. Child Development, $1977,48,570-578$.

Cromwel1, R.E., Olson, D.H., and Fournier, David. Tools and techniques for diagnosis in marital and family therapy. Family Process, 1976, 15, 1-49.

Glaser, D. The effectiveness of a prison and parole system. Indianapolis: Bobbs-Merri11, 1964.

Hunt, J. McV. Traditional personality theory in the light of recent evidence. American Scientist, 1965, 53, $80-96$.

James, C. and Hesselbrock, V. Perceived family environment and school adjustment of children of schizophrenics. Unpublished paper presented at the Amertcan Psychology Assoctation Convention,. Washington, D.C., 1976.

Kovel, J. A complete ruide to therapy. New York: Pantheon Books, 1976.

Lew18, J.M., Beavers, W.R., Gossett, J.F., and Phillips, V.A. No single thread: psychological health in family systems. New York: Brunner/Mazel, Inc., 1976.

Maddi, S. Personality theories: a comparative analrsis, Homewood, I11ino1s: Dorsey, 1968.

McCord, W., McCord, J., and Howard, A. Familial correlates of aggression in nondelinquent male children. Journal of Abnormal and Soctal Psychology, 1961, 62, 79-93.

Minuchin, S. Families and family therapye Canbridge, Mass: Harvard Vafrersity Press, 1974. 
Minuchin, S ., Montalvo, B., Guerney, B.G. Jr., Rosman, B.L., and Schumer, F. Families of the slums: an exploration of thetr structure and treatment, New Yorks Basic Books, 1967.

Moos, Rudolf H. Eraluating correctional and community settings, New Yorks Wiley, 1974a.

Moos, Rudolf $H$. Evaluating treatment environments, New York: Wiley, $1974 \mathrm{~b}$.

Moos, Rudolf H. Family environment scale preliminary manual. Social Ecology Laboratory, Stanford University, 1974c.

Moos, Rudolf H. Family, work, and group environment scales manual. Palo Alto, Callfornia: Consulting Psychologlets Press, Inc., $1974 d$.

Moos, R., Bromet, E., Tsu, V., and Moos, B. Social environments in families of treated alcoholics. Unpublished paper. Social Ecology Laboratory, Stanford Univorsity, 1976.

Moos, R. and Moos, B. A typology of family social environments. Family Process, 1976, 15, 357-371.

Mosteller, F., Rourke, R.E.K., Thomas, G. Jr. Probability with otatistical applications. Addison-Wesley PubIIshing Company, Inc., 1961.

Murray, Henry A. Some proposals for a theory of personality.

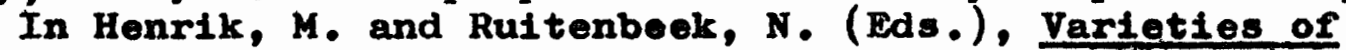
personality theory, Dutton and Co,. Inc., 1964, 184195.

Rosenthal, M. Effects of perent training groups on behavior change in target children, durability, generalization, and patterns of family interaction. Unpublished doctoral dissertation, University of Cincinnati, 1975.

Satix, Virginia. Conioint family therapy, revised edition. Palo Alto, California: Science and Behavior Books, Inc., 1967 .

Scoresby, A.L. and Christensen, B. Differences in interaction and environmental conditions of clinic and nonclinic families: implication for counselors. Journal of Marriage and Family Counseling, 1976, 2, 63-71.

Singer, M. Delinquency and family disciplinary configurations. Archives of General Psychiatry, 1974, 21 , 795-798. 
Straus, M.A. Fantly meesurement techntquer, Minnoapolis: University of Minnessota Press, 1969.

SundberE, N.D., TYlor, L.E., and Taplin, J.R. Clinical parcholofr: expending horizons, Now York: Meredith Corporation, 1973.

Walker, H.M. Walker problem behavior identiflcation checklist manual. Western Psychological Services, 1970.

Wetzel, J.W. Dependence upon unsustaining environments as an antecedent variable of depression. Unpublished doctoral diseertation, George Warren Brown School of Social Work, Washington University, St. Louls, Mo., 1976. 


\section{APPENDIX}

\section{THERAPIST RATING SCALE}

Date:

Family Name

Number of Children

Single Parent

Rater

After seeing this family together at least twice, please rate them on the following scale by marking the number which describes their level of functioning as a family. Please do not discuss this rating with other therapists.

1 BARELY FUNCTIONING: almost no positive interaction between members; severe communication problems; no enjoyment of family life; no problem-solving abilities; disintegrating.

2 LIMITED FUNCTIONING: occasional positive interaction between some members; communication between members usually a problem; little enjoyment of family life; minimal problem-solving abilities.

3 MODERATE FUNCTIONING: occasional positive interaction between all members; communication problems apparent; but not intense; some members moderately enjoy family life; problem solving abilities impaired. Maintaining.

4 ADEQUATE FUNCTIONING: some positive interaction between all members; combinication between members is fair; all members moderately enjoy family life problem solvins abilities fair.

5. STRONG FUNCTIONING: a lot of positive interaction among all members; communication difficulties minimal; all members enjoy family life; good problem solving abilities. Growth-producing. 